\title{
UPAYA MENINGKATKAN AKTIVITAS SISWA DALAM MATERI ATURAN SINUS DAN COSINUS MELALUI METODE INQUIRY DI KELAS X IPA.1 SMA NEGERI 1 MUARO JAMBI
}

\author{
S. Waltuti ${ }^{1}$ \\ Guru SMAN 1 Muaro Jambi ${ }^{1}$ \\ Email : -
}

\begin{abstract}
ABSTRAK
Tujuan dari penelitian ini adalah untuk mengetahui bagaimana metode inkuiri dapat meningkatkan hasil belajar siswa tentang teori matematika. Metode penelitian ini adalah penelitian tindakan kelas. Pelaksanaan penelitian ini menggunakan dua siklus, di mana setiap siklus terdiri dari dua pertemuan. Data yang digunakan dalam penelitian ini adalah catatan lapangan dan format observasi. Analisis data menggunakan sistem persentase untuk melihat aktivitas siswa, khususnya untuk topik sinus pelajaran dan kosinus. Pengolahan hasil belajar menggunakan teori statistik dengan mencari nilai rata-rata, daya serap dan kriteria minimum pada akhir siklus. Hasil penelitian menunjukkan bahwa metode inkuiri dapat meningkatkan hasil belajar siswa dalam proses pembelajaran. Hal ini ditunjukkan oleh peningkatan skor siswa yang signifikan dari 53,12\% menjadi 70,83\%. Rata-rata hasil belajar siswa pada siklus I dan II adalah 58,91 dan 75,78. Kelengkapan hasil belajar siswa meningkat dari 53, $12 \%$ menjadi 87,50\%.
\end{abstract}

Kata kunci:

Metode Penyelidikan; Aturan Sine dan Cos; Aktivitas Siswa,

\begin{abstract}
The aim of this research is to find out how the inquiry method can improve the students learning outcomes about mathematical theories. The method of this research was classroom action research. The implementation of this research used two cycles, in which each cycle consisted of two meetings. The data used in this research were field notes and observation format. The data analysis used a percentage system in order to see the students' activity, specifically for the topic of the lesson sine and cosine. Processing of learning results used statistical theory by finding the average value, absorption and minimum criteria at the end of the cycle. The results showed that the inquiry method can improve the students learning outcomes in the learning process. It was indicated by the significant improvement of students's score from $53.12 \%$ to $70.83 \%$.The average of student learning outcomes of cycles I and II were 58.91 and 75.78.The completeness of student learning outcomes increased from 53, $12 \%$ to $87.50 \%$.
\end{abstract}

\section{Keywords:}

Inquiry Method; Rules of Sine and Cosine; Students' Activity,

\section{PENDAHULUAN}

Perubahan paradigma pembelajaran di sekolah dari berpusat pada guru menuju pembelajaran yang berpusat pada siswa terasa gaungnya melalui diskusi, pelatihan yang terkait dengan pembelajaran, bahkan sampai dengan implementasi model-model pembelajaran melalui Lesson Study. Melaksanakan pembelajaran yang berpusat kepada siswa berarti guru sebagai fasilitator, perlu membantu siswa untuk menentukan tujuan yang ingin dicapai, mendorong siswa untuk dapat menilai hasil belajarnya sendiri, membantu mereka untuk bekerja dalam kelompok, dan memastikan agar mereka mengetahui kekuatan diri dengan perubahan yang terjadi di lingkungan sosial dan lingkungan kerja, serta mampu mengembangkan diri sesuai dengan perkembangan ilmu dan teknologi.

$$
\text { Pelajaran matematika sering }
$$




\section{$\pi$ (Phi)}

dianggap pelajaran yangrumit dan membosankan, hingga akhirnya siswa tidak menyukai pelajaran matematika yang menyebabkan hasil belajar siswa menjadi rendah. Hal ini sangat mempengaruhi proses belajar mengajar dan opini ini tentulah akan menjadi tantangan bagi para pengajar agar dapat menampilkan citra matematika sebagai pelajaran yang menyenangkan. Pembelajaran matematika sering dikritik, karena menekankan pada menghapalkan rumus-rumus. Pada kurikulum yang baru penekanan pembelajaran adalah pada penalaran matematika (serta bentuk-bentuk kemampuan nalar tingkat tinggi lainnya seperti analisis, sintetis, aplikasi dan evaluasi). Sesungguhnya semua kemampuan sering dapat diasah melalui aktivitas penyelesaian masalah (problem salving). Dengan kemampuan ini siswa dapat menggunakan matematika untuk menghadapi masalah real yang seringkali kompleks, siswa perlu menguasai bagaimana mengumpulkan fakta yang relevan, merumuskan konjektur, membangun model, membuat contoh penyangkal dan menyusun argumentasi yang kokoh dan logis sebagaimana hasilnya diharapkan siswa mengembangkan sikap skeptik yang fair dan mempunyai ketajaman analisis yang sangat dihargai. Pemecahan masalah merupakan bagian dari kurukulum matematika yang sangat penting karena dalam proses pembelajaran maupun penyelesaiannya, siswa dimungkinkan memperoleh pengalaman menggunakan pengetahuan serta ketrampilan yang sudah dimiliki untuk diterapkan pada pemecahan masalah yang bersifat tidak rutin. Melalui kegiatan ini aspek-aspek kemampuan matematika penting seperti penerapan aturan pada masalah tidak rutin, penemuan pola, penggeneralisasian, komunikasi matematik, dan lain-lain dapat dikembangkan secara lebih baik. Namun demikian, kenyataan dilapangan menunjukkan bahwa kegiatan pemecahan masalah dalam proses pembelajaran matematika belum dijadikan sebagai kegiatan utama.

Berbagai cara dapat dilakukan agar hasil belajar siswa menjadi lebih baik dan optimal. Pada saat ini umumnya proses pembelajaran di sekolah berpusat pada guru dan menjadikan guru sebagai pusat pembelajaran, hanya memindahkan pengetahuannya kepada siswa sehingga jarang sekali siswa dilibatkan secara aktif dalam proses pembelajaran. Akibat yang ditimbulkan adalah siswa hanya sebagai penerima yang pasif tidak dapat mengembangkan potensi-potensi yang ada di dalam dirinya. Untuk mengatasi permasalahan diatas penulis berasumsi bahwa siswa harus diberikan bimbingan dalam menemukan rumus pada materi aturan sinus dan kosinus sehingga siswa mempunyai kemampuan dan ketrampilan dalam membahas soal.

Kemampuan siswa dalam menjawab soal berhubungan erat dengan kemampuanberpikir dan bernalar. Kemampuan berpikir dan menalar ini dipengaruhi oleh berbagai unsur seperti tingkat intelegensi. Dengan demikian bahasa yang digunakan dalam membuat soal haruslah bahasa yang mudah dipahami oleh siswa. Kesalahan dalam penggunaan bahasa mempengaruhi tingkat kesulitan mnemahami konsep, sehingga kemampuan berpikir dan bernalarkan soal tidak dapat terlihat, dengan demikian dapat melemahkan minat dan motivasi belajar siswa.

Metode Inquiry ialah metode mengajar yang paling mirip dengan metode penemuan. Beberapa perbedaannya adalah sebagai berikut : Mengajar dengan penemuan biasanya dilakukan dengan ekspositori dalam kelompok-kelompok kecil (di laboratorium, bengkel atau kelas). Tetapi mengajar dengan metode inquiry dapat dilakukan melalui ekspositori, kelompok, dan secara sendiri-sendiri. 


\section{$\pi$ (Phi)}

Sebuah tujuan mengajar dengan inquiry adalah agar siswa tahu dan belajar metode ilmiah dengan inquiry dan mampu mentransfernya kedalam situasi lain. Metode ini terdiri atas 4 tahap :

1. Guru merangsang siswa dengan pertanyaan, masalah, permainan dan teka teki.

2 Sebagai jawaban atas rangsangan yang diterimanya, siswa menentukan prosedur mencari dan mengumpulkan informasi atau data yang diperlukannya untuk memecahkan pertanyaanpertanyaan dan masalah.

3. Siswa menghayati pengetahuan yang diperolehnya dengan inquiry yang baru dilaksanakan.

4. Siswa menganalisis metode inquiry dan prosedur yang ditemukan untuk dijadikan metode umum yang dapat diterapkannya ke situasi lain.

\section{METODE PENELITIAN}

Penelitian tindakan kelas ini dilaksanakan di SMA Negeri 1 Muaro Jambi. Adapun yang menjadi subyek dalam penelitian ini adalah siswa kelas $X$ IPA.1 Tahun Ajaran 2016/2017 yang berjumlah 32 orang. Penelitian dilakukan dalam dua siklus dan tiap siklus dua kali pertemuan.

Teknik dan alat pengumpul data yang digunakan dalam penelitian tindakan kelas ini adalah :

a Pedoman observasi untuk mengecek aktivitas siswa berdasarkan indikator yang telah ditentukan sebelumnya.

b. Catatan tentang kejadian yang terjadi selama tindakan diberikan, baik yang positif maupun yang negatif.

c. Lembar tes untuk melihat hasil belajar siswa.

Data hasil penelitian tindakan kelas ini akandianalisissecara kuantitatif dengan melihat persentase peningkatan aktifitas dan hasil belajar siswa. Data hasil belajar (hasil tes) yang diperoleh pada setiap siklus di ukur melalui instrumen tes. Data diolah

dan dianalisis dengan rumus sebagai berikut :

$N=\frac{X}{\sum X} x 100$

Keterangan :

$\mathrm{N}=$ Nilai

$\mathrm{X}=$ Banyaknya jawaban yang benar

$\sum X=$ Jumlah soal

Untuk mendapatkan nilai rata-rata akhir dari setiap siklus, maka digunakan rumus sebagai berikut :

$X=\frac{\sum_{i=1}^{n} x}{N}$

Keterangan :

$\mathrm{X}=$ Nilai rata-rata

$\sum_{i=1}^{n} x=$ Jumlah seluruh nilai

$\mathrm{N}=$ Jumlah siswa

Hasil observasi terhadap aktivitas siswa diolah dan dianalisis dengan rumus sebagai berikut :

$A=\frac{N a}{N} \times 100 \%$

Keterangan :

$\mathrm{A}=$ Aktivitas siswa

$\mathrm{Na}=$ Jumlah siswa yang aktif

$\mathrm{N}=$ Jumlah siswa keseluruhan

\section{HASIL DAN PEMBAHASAN}

Berdasarkan hasil pengamatan aktifitas siswa untuk siklus 1 menunjukkan bahwa kemampuan siswa untuk menggunakan rumus aturan sinus $40,62 \%$. Menyelesaikan menjadi sebuah rumus aturan sinus baru 56,25\%. Mengidentifikasi soal aturan sinus mencapai 50\%. Untuk menggunakan rumus yang sesuai dengan soal $62,50 \%$. Sedangkan ketelitian dalam menghitung hanya $40,62 \%$. Keaktifan siswa dalam merespon/memberi tanggapan 68,75\%. Secara keseluruhan keaktifan siswa untuk materi aturan sinus masih dalam kategori 


\section{$\pi$ (Phi)}

kurang aktif atau 53,12\%.

Berdasarkan Tabel 3 merupakan analisis dari hasil tes siklus I untuk materi aturan sinus dengan jumlah siswa yang ikut tes 32 orang di peroleh nilai rata-rata 58,91 , nilai yang paling tinggi 90 hanya diperoleh 1 orang siswa, nilai yang sering muncul 70, nilai terendah 25 yaitu sebanyak 2 orang siswa. Jika dilihat dari nilai rata-rata, nilai yang sering muncul semuanya sudah memenuhi syarat tuntas yaitu 70, namun jika melihat secara individu masih ada siswa yang belum tuntas atau dibawah Kriteria Ketuntasan Minimal (KKM) sebanyak 15 orang. Ini berarti perlu ada peningkatan atau perbaikan baik strategi atau penguasaan konsep, melalui pengayaan dan remedial.Hasil belajar tersebutbelum signifikan dalam mencapai ketuntasan belajar yang diharapkan. Oleh karena itu, perlu dilanjutkan dengan diadakan tindakan siklus II.

Pada Tabel 2 juga ada hasil pengamatan aktifitas siswa pada siklus II untuk materi aturan cosinus dimana ketepatan siswa dalam menggunakan rumus aturan cosinus $62,50 \%$. 68,75\% siswa sudah mampu menyelesaikan menjadi sebuah rumus aturan cosinus sehingga untuk mengidentifikasi soal aturan cosinus $71,88 \%$ sudah mulai baik. Dan $78,12 \%$ siswa sudah mulai baik dalam menggunakan rumus yang sesuai dengan soal. Siswa sudah mulai teliti dalam menghitung yaitu $62,50 \%$. Keaktifan siswa dalam merespon/memberi tanggapansudah sangat baik $81,25 \%$. Secara keseluruhan rata-rata aktivitas siswa sudah meningkat yaitu sebesar $70,83 \%$ berarti berada dalam kategori aktif.

Analisis dari hasil tes siklus II untuk materi aturan cosinus dengan jumlah siswa 32 orang diperoleh nilai rata-rata 75,78 . Nilai yang sering muncul 70 dan 75 , nilai terendah 40 sebanyak 1 orang sedangkan nilai tertinggi 90 dan 95 sebanyak 2 orang. Secara rata-rata memang sudah melibihi KKM namun secara individu 4 siswa masih perlu bimbingan yang maksimal untuk materi aturan cosinus seperti terlihat pada Tabel 3.

Tabel 2. Hasil Observasi Aktivitas Siswa pada Siklus I dan II

\begin{tabular}{|c|c|c|c|c|c|}
\hline \multirow[t]{2}{*}{ No } & \multirow[t]{2}{*}{ Aktivitas yang diamati } & \multicolumn{2}{|c|}{ Siklus I } & \multicolumn{2}{|c|}{ Siklus II } \\
\hline & & Jumlah & Persentase & Jumlah & Persentase \\
\hline 1 & $\begin{array}{l}\text { Ketepatan siswa dalam } \\
\text { menggunakan rumus } \\
\text { aturan sinus dan cosinus }\end{array}$ & 13 & $40,62 \%$ & 20 & $62,50 \%$ \\
\hline 2 & $\begin{array}{l}\text { Menyelesaikan menjadi } \\
\text { sebuah rumus aturan sinus } \\
\text { dan cosinus }\end{array}$ & 18 & $56,25 \%$ & 22 & $68,75 \%$ \\
\hline 3 & $\begin{array}{l}\text { Mengidentifikasi soal } \\
\text { aturan sinus dan cosinus }\end{array}$ & 16 & $50,00 \%$ & 23 & $71,88 \%$ \\
\hline 4 & $\begin{array}{l}\text { Menggunakan rumus yang } \\
\text { sesuai dengan soal }\end{array}$ & 20 & $62,50 \%$ & 25 & $78,12 \%$ \\
\hline 5 & $\begin{array}{l}\text { Ketelitian dalam } \\
\text { menghitung }\end{array}$ & 13 & $40,62 \%$ & 20 & $62,50 \%$ \\
\hline \multirow[t]{2}{*}{6} & $\begin{array}{l}\text { Keaktifan siswa dalam } \\
\text { merespon/ memberi } \\
\text { tanggapan }\end{array}$ & 22 & $68,75 \%$ & 26 & $81,25 \%$ \\
\hline & \multicolumn{2}{|l|}{ Rata-rata } & $53,12 \%$ & & $70,83 \%$ \\
\hline
\end{tabular}


Tabel 3. Hasil Belajar Siswa (Kognitif) pada Siklus 1 dan II

\begin{tabular}{c|c|c|c|c|c|}
\hline \multirow{2}{*}{ No } & \multirow{2}{*}{ Interval Nilai } & \multicolumn{2}{|c|}{ Siklus I } & \multicolumn{2}{c|}{ Siklus II } \\
\cline { 3 - 6 } & & $\begin{array}{c}\text { Jumlah } \\
\text { Siswa }\end{array}$ & $\begin{array}{c}\text { Persentase } \\
(\%)\end{array}$ & $\begin{array}{c}\text { Jumlah } \\
\text { Siswa }\end{array}$ & $\begin{array}{c}\text { Persentase } \\
(\%)\end{array}$ \\
\hline 1 & $90-100$ & 1 & 3,12 & 2 & 6,25 \\
\hline 2 & $80-89$ & 2 & 3,12 & 7 & 21,87 \\
\hline 3 & $70-79$ & 14 & 25 & 19 & 59,37 \\
\hline 4 & $60-69$ & 1 & 9,37 & 2 & 6,25 \\
\hline 5 & $50-59$ & 3 & 12,5 & 1 & 3,12 \\
\hline 6 & $40-49$ & 6 & 25 & 1 & 3,12 \\
\hline 7 & $30-39$ & 3 & 9,37 & 0 & 0 \\
\hline 8 & $0-29$ & 2 & 6,25 & 0 & 0 \\
\hline & Jumlah & 32 & 100 & 32 & 100 \\
\hline & Rata-rata & & 58,91 & & 75,78 \\
\hline & Daya serap & & 58,91 & & 75,78 \\
\hline & Ketuntasan & & $53,12 \%$ & & 87,50 \\
\hline
\end{tabular}

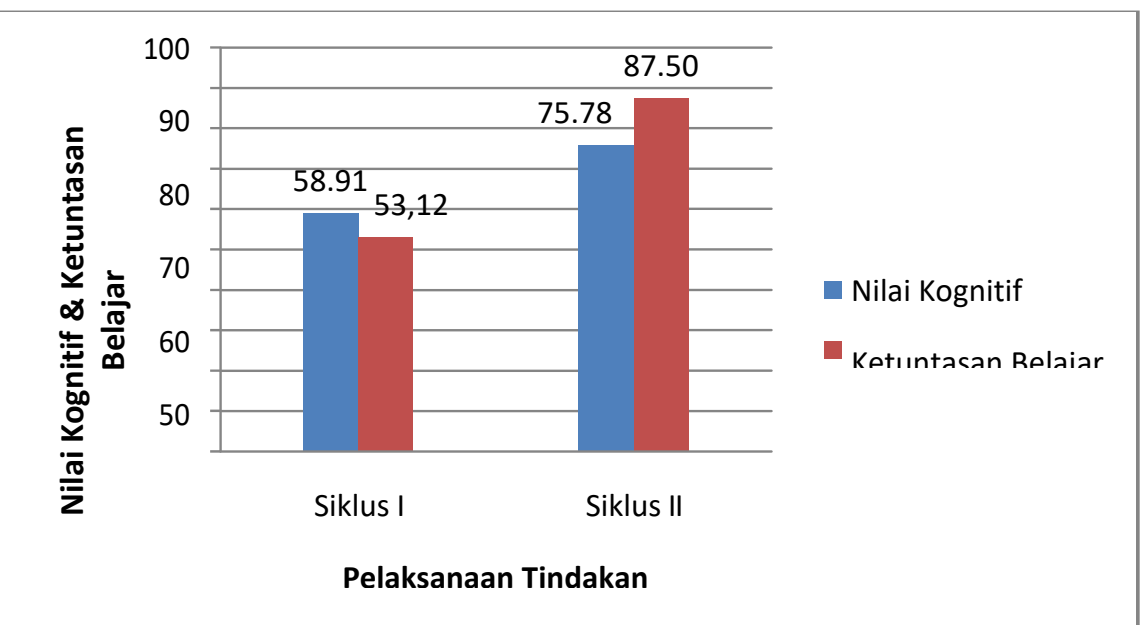

Gambar 1. Grafik Perbandingan Hasil Belajar (Kognitif) dan Ketuntasan Belajar Siswa pada Siklus I dan Siklus II

Dari proses belajar mengajar menggunakan metode inquiry yang sudah dilakukam, hasil yang diperoleh siswa pada setiap siklus mengalami peningkatan. Hal ini bisa dijelaskan dari hasil obeservasi pada siklus I dimana aktivitas siswa dalam proses pembelajaran masih perlu peningkatan dan belum memenuhi indikator keberhasilan. Hasil rata-rata yang diperoleh dari observasi adalah 53,12\%. Pada siklus Isulit mengajak siswa untuk mandiri dalam menemukan rumus karena siswa belum terbiasa dengan penemuan (inquiry).Untuk itu perlu pendekatan individu agar siswa tereksplorasi untuk mengingat rumus- rumus yang ada kaitannya dengan rumus berikutnya.
Sedangkan pada siklus II terlihat adanya peningkatan aktivitas siswa dalam belajar menggunakan metode inquiry yang selama ini siswa hanya menerima rumus langsung dari guru tanpa siswa yang menemukan.

Dengan menggunakan metode inquiry siswa sudah dapat melakukan kegiatan penemuan rumus sendiri walaupun masih dibimbing oleh guru namun bimbingan guru itu hanya sebagai motivator.Siswa lebih fokus dalam proses belajar mengajar. Hal ini dapat dilihat dari hasil observasi dengan nilai rata-rata $70,83 \%$ meningkat dari predikat 'kurang aktif' pada siklus I menjadi predikat 'aktif' pada siklus II.

Peningkatan ini juga dapat dilihat 


\section{$\pi$ (Phi)}

dari hasil tes pada siklus II diperoleh tingkat ketuntasan belajar siswa sebesar $87,50 \%$ berada dalam kategori 'baik'. Hasil ini meningkat dari hasil ketuntasan belajar siswa pada siklus I yaitu $53,12 \%$. Hasil rata-rata tes kognitif siswa meningkat dari 58,91 pada siklus I menjadi 75,78 pada siklus II. Secara klasikal hasil belajar sudah mencapai ketuntasan dan hasil yang diperoleh ini menunjukkan hasil yang sangat baik dan aktivitas pembelajaran berjalan dengan baik. Pada gambar 1 dapat dilihat perbandingan hasil belajar (kognitif) dan ketuntasan belajar siswa pada siklus I dan siklus II.

\section{SIMPULAN DAN SARAN}

Berdasarkan hasil penelitian dan pembahasan dapat disimpulkan bahwa penggunaan metode inquiry pada pembelajaran matematika khususnya pada materi aturan sinus dan cosinus dapat meningkatkan hasil belajarsiswa kelas $\mathrm{X}$ IPA 1 SMA Negeri 1 Muaro Jambi.Hal ini ditandai dengan meningkatnyanilai ratarata hasil belajar siswa dari 58,91 dengan ketuntasan $53,12 \%$ menjadi 75,78 dengan ketuntasan klasikal $87,50 \%$. Hasil data observasi, penggunaan metode inquiry dapat meningkatkan aktivitas siswa dari $53,12 \%$ pada siklus I, menjadi $87,50 \%$ pada siklus II.

\section{DAFTAR PUSTAKA}

Sujono.1998. Pengajaran Matematika untuk Sekolah Menengah.Jakarta: Depdikbud.

Tim MKPBM.2001. Strategi Pembelajaran Matematika Kontemporer. Bandung: Universitas Pendidikan Indonesia..

Djamarah, S.B \& Zain, A. 2002. Strategi Belajar Mengajar. Jakarta: Rineka Cipta.

Depdiknas. 2003. Pedoman KhususPengembangan Silabus dan Penilaian, Direktorat Jenderal

Pendidikan Dasar dan Menengah. Direktorat Pembinaan SMA, Ditjen Pendidikan Menegah. 2013, Model Penilaian Peserta Didik SMA. Jakarta: Kementrian Pendidikan dan Kebudayaan. 